\title{
The presence of facial nerve weakness on diagnosis of a parotid gland malignant process
}

\author{
Małgorzata Wierzbicka • Tomasz Kopeć • Witold Szyfter • \\ Thomas Kereiakes · Grażyna Bem
}

Received: 11 October 2011 / Accepted: 6 December 2011 / Published online: 18 December 2011

(C) The Author(s) 2011. This article is published with open access at Springerlink.com

\begin{abstract}
The objectives of this article are to assess the frequency and significance of facial paralysis and undiagnosed nerve infiltration in patients with parotid malignancies. 103 patients with parotid gland malignancies were treated in a single institution, the tertiary center for ENT at the University Department in Poznan between 1996 and 2006. Facial palsy at the initial presentation was found in 32 patients. The stage of the primary tumor in the examined group of 103 patients is as follows: $20-\mathrm{T} 1,31-\mathrm{T} 2,20-\mathrm{T} 3$, 32-T4. The correlation between facial nerve function before treatment and patients' characteristics, including the treatment methods, were analyzed. Intact facial nerve function at patient presentation was a very strong prognostic factor determining the treatment and final outcome for malignant neoplasms of parotid gland. Similarly, $T$ stage and a high-grade malignant histology had a direct influence on the duration of patients' survival.
\end{abstract}

Keywords Parotid malignant tumors $\cdot$ Facial nerve paralysis

\section{Introduction}

Parotid tumors typically manifest as a painless lump in the preauricular region. The majority are benign; however, inflammatory symptoms (pain, reddened skin) and facial

M. Wierzbicka $\cdot$ T. Kopeć $(\bowtie) \cdot$ W. Szyfter $\cdot$ G. Bem ENT Department, Karol Marcinkowski Medical University in Poznań, Przybyszewski Street 49, 60355 Poznań, Poland e-mail: tkopec@ump.edu.pl

T. Kereiakes

Cincinnati Head and Neck, Cincinnati, OH, USA asymmetry are characteristics that strongly suggest a malignant lesion. The duration of complaints in such a histologically diverse group of benign tumors and malignancies can vary greatly. Facial nerve weakness alarms the patient, family, and General Practitioner and prompts an earlier referral and consultation. Preoperative facial nerve palsy is a manifestation of malignant infiltration and so far, the only preoperative indicator for planning total parotidectomy with nerve resection and facial reanimation [3, 6, 15]. When the facial nerve function is intact, early involvement with tumor cannot be definitively ruled out. Preoperative imaging (ultrasonography, computed tomography, and magnetic resonance) do not have the resolution for nerve structure visualization [5]. Therefore, intraoperative nerve assessment is crucial in the decision making process as to whether the nerve should be resected.

The aims of the study are to (1) assess the frequency of facial paralysis and undiagnosed nerve infiltration in patients with parotid malignancies; (2) analyze the duration of symptoms before presentation; and (3) define the risk factors for nerve impairment and the impact of facial nerve involvement on treatment methods, outcomes, and survival.

\section{Materials}

One hundred and three patients had surgery for parotid gland malignancies in a single institution, the tertiary center for ENT as the University Department in Poznań between 1996 and 2006. Facial palsy, assessed in House-Brackmann 6-score scale (H-B), was identified at the initial presentation in 32 patients: 28 had total facial palsy (H-B 6) and 4 had partial facial palsy (H-B 2-5). In five other patients, intra-operative features of facial nerve infiltration were found although the facial mobility was normal preoperatively 
(H-B 1). The study group included 53 women and 50 men ranging in age from 12 to 87 years, with a mean age of 55 years.

The tumor histology was assessed according to WHO_-1991 classification, modified in 2003: adenoid cystic carcinoma-27, acinic cell carcinoma -9, undifferentiated carcinoma-8, mucoepidermoid carcinoma-8, squamous cell carcinoma-18, anaplastic carcinoma-3, adenocarcinoma-7, lymphoma malignum-5, ex-pleomorphic carcinoma-6, and metastases-12. Twelve cases assessed on the base of histology as metastases had primaries in: skin (two malignant melanoma), kidney (two clarocellular cancer), prostatic gland (two adenocarcinoma), and upper aerodigestive tract (six squamous cell carcinoma). In preoperative oligobiopsy atypical cell or malignant cell were diagnosed in all cases from "metastases group." Thus, these patients were primarily graded with $\mathrm{T}$ stage. Finally, 2 weeks after the procedure, the pathological examination revealed metastases and the further diagnostics of the primary was carried up. We would underline the difference between primary salivary tumors and metastatic process. In further analysis, this group would be distinguished and its outcomes compared with other histological entities.

The stage of the primary tumor in the examined group of 103 patients is as follows: 20-T1, 31- T2, 20- T3, 32-T4a. The diameter of the tumors in preoperative imaging (ultrasonography, computed tomography, or magnetic resonance imaging) ranged from 1 to $9 \mathrm{~cm}$, with a mean $3 \mathrm{~cm}$.

The duration of symptoms before the initial presentation ranged between 1 and 120 months, with a mean of 12 months. The mean duration of complaints in patients with facial palsy was 16.8 months and the mean duration of complaints in patients without facial palsy was 14.1 months. The duration of complaints for a particular histologic diagnosis was as follows: adenoid cystic carcinoma -15 months, acinic cell carcinoma -7 months, undifferentiated carcinoma-7 months, mucoepidermoid carcinoma-15 months, squamous cell carcinoma -6 months, and adenocarcinoma-34 months.

Taking into consideration the cancer histology, facial nerve paresis was noted in: 11 out of 27 with adenoid cystic, 5 out of 9 with acinic cell, 4 out of 8 with undifferentiated, 3 out of 8 with mucoepidermoid, 6 out of 18 with squamous cell, 4 out of 6 with ex-pleomorphic cancer, 1 out of 7 with adenocarcinoma, and in 0 out of 20 patients from the rest of the group ( 12 with metastases in parotid, 5 with lymphoma malignum, and 3 with anaplastic carcinoma).

All patients were treated surgically with the intent for complete resection. In most cases, the facial nerve was identified by anterograde dissection, but in some it was identified by the retrograde technique. A cable graft, when used, was harvested from the greater auricular nerve. All patients with nerve palsy were given adjuvant radiotherapy.
The data were analyzed statistically by Chi-square test to compare categorical variables between groups or non-parametric Kruskal-Wallis and Mann-Whitney test. The overall survival results were calculated using the Kaplan-Meier method and differences were analyzed by the log-rank test.

\section{Results}

The correlation between facial nerve function before treatment and patients' characteristics, including the treatment methods, were analyzed.

Facial paresis at the initial presentation was found in 32 patients (28 total, 4 partial), equally distributed in male and female patients. The duration of symptoms in both groups: with and without facial nerve paresis is shown in Table 1. The average duration of complaints before the initial presentation was 16.8 months in the paresis group, and 14.1 months for the non-paresis group. However, the difference did not achieve a statistical significance (Mann-Whitney test: $p=0.121)$.

Taking into consideration tumor histology, the shortest duration of symptoms to presentation was found in squamous cell cancers - 6.2 months, followed by metastasis to the parotid-7.8 months, then adenoid cystic carcinoma-15.3 months, and acinic cell cancer after 55 months. The results were statistically significant (Kruskal-Wallis test: $p<0.001)$. There was no statistical difference between the histologic types with regard to the propensity toward facial nerve paresis. Tumor diameter and occurrence of facial palsy were compared. Of the 32 patients with paresis, 4 were in tumors $<2 \mathrm{~cm} ; 7$ in tumors between 2 and $4 \mathrm{~cm}$; and 21 in tumors $>4 \mathrm{~cm}$ (Table 2 ). The correlation between tumor size and paresis is statistically evident (Chi-quadrate test $p<0.001)$.

During the study period, 778 parotidectomies were performed in our institution. Of this group, there were 103 malignancies. Partial lateral parotidectomy was performed in 37 patients, although the majority of the cases treated by this technique took place before the year 2000. Between 2001 and 2006, lateral parotidectomies and total parotidectomies were predominantly performed. The analysis of surgical treatment of parotid malignancies included the

Table 1 Correlation between duration of symptoms and paresis of the facial nerve at the initial presentation

\begin{tabular}{llllll}
\hline $\begin{array}{l}\text { Paresis of the } \\
\text { facial nerve }\end{array}$ & $N$ & \multicolumn{4}{c}{ Duration of symptoms (months) } \\
\cline { 2 - 6 } & & Mean & $\begin{array}{l}\text { Standard } \\
\text { deviation }\end{array}$ & Minimum & Maximum \\
\hline Yes & 32 & 16.8 & 17.7 & 2.0 & 72.0 \\
No & 71 & 14.1 & 20.1 & 1.0 & 120.0 \\
\hline
\end{tabular}


Table 2 Correlation between tumor size and facial nerve paresis at the initial presentation

\begin{tabular}{lrrrr}
\hline $\begin{array}{l}\text { Paresis of } \\
\text { the facial } \\
\text { nerve }\end{array}$ & \multicolumn{2}{l}{ Tumor size } & \multicolumn{2}{l}{ All } \\
\cline { 2 - 4 } & $<2 \mathrm{~cm}$ & $<4 \mathrm{~cm}$ & $>4 \mathrm{~cm}$ & \\
\hline Yes & $4(12.5 \%)$ & $7(21.9 \%)$ & $21(65.7 \%)$ & $32(100.0 \%)$ \\
No & $15(21.1 \%)$ & $46(64.8 \%)$ & $10(14.1 \%)$ & $71(100.0 \%)$ \\
All & $19(18.4 \%)$ & $53(51.5 \%)$ & $31(30.1 \%)$ & $103(100.0 \%)$ \\
\hline
\end{tabular}

comparison of three different surgical techniques: tumor removal with a margin of healthy tissue, lateral parotidectomy, and total parotidectomy. In Table 3 , the choices of surgical procedures are presented. In patients with positive nodes $(\mathrm{N}+)$, neck dissection was performed, depending on the age of the patient, advanced stage of the cancer (T\&N), and the presence of facial nerve palsy. Importantly, this study compared the selection of three operating techniques: partial lateral parotidectomy, lateral parotidectomy, and total parotidectomy. Table 3 analyzes the factors of age, tumor size, nodal status, and facial nerve status compared to the choice of operation with or without neck dissection. There was no difference between the age groups when analyzes by treatment method, $\mathrm{T}$ stage, $\mathrm{N}$ stage, and facial nerve palsy. The status of the neck was compared to the risk of facial paralysis. 27 neck dissections (15 selective level II and III, and 12 radical) were performed on the 103 patients with parotid malignancies. Pathological examination of surgical specimens confirmed metastases in 20 patients $(\mathrm{pN}+)$. The positive nodal disease was not identified by pathologist in the primary specimen in any patient. The presence of positive lymph nodes was not a statistically significant risk factor for facial nerve involvement. Logline analysis performed for the following factors: the type of operation, $\mathrm{T}$ stage, $\mathrm{N}$ stage, nerve palsy, and age (categorized in two groups) revealed that the greatest influence on the chosen type of operation was $\mathrm{T}$ stage and facial nerve palsy. With higher T stage, the number of total parotidectomies performed increased and lateral parotidectomies decreased; however, this is noticed most clearly in the group of patients with facial nerve palsy.

Hundred percent of the facial nerve palsy group was treated by means of total parotidectomy ( 28 patients) or by lateral parotidectomy (4 patients). This is compared to the group without palsy, in which these more extensive procedures account for less than 50\% of the surgeries (Table 4). The correlation is statistically significant (Chi-quadrate test; $p<0.001$ ). In four patients with facial palsy, lateral parotidectomy can be explained by the small tumor volume restricted to the inferior pole of the gland and partial palsy including only the marginal branch of the facial nerve. Thus, on presentation, the facial nerve function was in H-B scale $2,2,2,3$, respectively, and only in one patient paresis progressed $(2 \rightarrow 3)$. In five patients without clinical evidence of nerve involvement, the neural infiltration was identified intra-operatively. In these patients, the anterograde technique was used to identify the main trunk and the retrograde technique to visualize two distal branches. The infiltrated segment was resected, and a cable graft was harvested for reanimation from the greater auricular nerve. Thus, in all five patients immediately after surgery the deterioration of facial function was striking $(1 \rightarrow 6)$, but in four of them in 1-year time rehabilitation, the improvement was noticed $(6 \rightarrow 3,4,4,4)$. The decision to not reconstruct the nerve in any of the 32 patients with previous palsy was made because of difficulties in securing a long enough proximal stump to perform epineural repair, or inadequate distal branches. In four patients aged $>80$, reconstruction was not performed because of poor general status.

In all patients, pathology was performed and the margins were assessed. Histological analysis revealed that in 18 out of 103 cases, free margins were not obtained (resection margins incomplete or close). This included 8 (25\%) patients with facial nerve paresis and $10(14 \%)$ patients

Table 3 Treatment methods

\begin{tabular}{|c|c|c|c|c|c|c|}
\hline \multirow{2}{*}{$\begin{array}{l}\text { Treatment of } \\
\text { primary tumor }\end{array}$} & \multicolumn{2}{|c|}{$\begin{array}{l}\text { Partial lateral parotidectomy } \\
37 \text { patients }\end{array}$} & \multicolumn{2}{|c|}{$\begin{array}{l}\text { Lateral parotidectomy } \\
34 \text { patients }\end{array}$} & \multicolumn{2}{|c|}{$\begin{array}{l}\text { Total parotidectomy } \\
32 \text { patients }\end{array}$} \\
\hline & N0 31 & Neck dissection 6 & N0 28 & Neck dissection 6 & N0 17 & Neck dissection 15 \\
\hline \multicolumn{7}{|l|}{ Age } \\
\hline$>57$ years & 17 & 5 & 10 & 2 & 12 & 10 \\
\hline$<57$ years & 14 & 1 & 18 & 4 & 5 & 5 \\
\hline \multirow[t]{3}{*}{$\mathrm{T}$} & $\mathrm{T} 1-19$ & T1-1 & $\mathrm{T} 2-11$ & $\mathrm{~T} 2-3$ & T3-2 & T3-2 \\
\hline & $\mathrm{T} 2-12$ & $\mathrm{~T} 2-5$ & T3-13 & T3-3 & $\mathrm{T} 4-15$ & $\mathrm{~T} 4-13$ \\
\hline & & & $\mathrm{T} 4-4$ & & & \\
\hline \multirow[t]{2}{*}{$\mathrm{N}$} & N0-31 & N0-4 & N0-28 & N0-1 & N0-17 & N0-2 \\
\hline & & N1-2 & & N1-5 & & N1-13 \\
\hline Paresis of the facial nerve & 0 & 0 & 4 & 0 & 16 & 12 \\
\hline
\end{tabular}


Table 4 Occurance of facial nerve paresis and treatment method

\begin{tabular}{llll}
\hline Treatment & \multicolumn{2}{l}{ Facial nerve palsy } & \multirow{2}{*}{ All } \\
\cline { 2 - 3 } & Yes & No & \\
\hline $\begin{array}{l}\text { Partial lateral } \\
\quad \text { parotidectomy }\end{array}$ & $0(0.0 \%)$ & $37(52.1 \%)$ & $37(35.9 \%)$ \\
Lateral parotidectomy & $4^{\mathrm{a}}(12.5 \%)$ & $30 / 1^{\mathrm{b}}(42.3 \%)$ & $34(33.0 \%)$ \\
Total parotidectomy & $28(87.5 \%)$ & $4 / 4^{\mathrm{b}}(5.6 \%)$ & $32(31.1 \%)$ \\
All & $32(100.0 \%)$ & $71(100.0 \%)$ & $103(100.0 \%)$ \\
\hline
\end{tabular}

${ }^{a}$ Facial nerve palsy including only a marginal branch

${ }^{\mathrm{b}}$ Facial nerve resection with immediate reconstruction

Table 5 Comparison of recurrence frequency in patients with and without facial nerve paresis

\begin{tabular}{lccc}
\hline \multirow{2}{*}{$\begin{array}{l}\text { Local } \\
\text { recurrence }\end{array}$} & \multicolumn{2}{l}{ Facial nerve paresis } & \multirow{2}{*}{ All } \\
\cline { 2 - 3 } & Yes & No & \\
\hline No & $26(81.3 \%)$ & $66(93.0 \%)$ & $92(89.3 \%)$ \\
Yes & $6(18.8 \%)$ & $5(7.0 \%)$ & $11(10.7 \%)$ \\
All & $32(100.0 \%)$ & $71(100.0 \%)$ & $103(100.0 \%)$ \\
\hline
\end{tabular}

without paresis. The difference was not statistically significant.

Local-regional control and disease-free survival were studied in the all of patients with parotid malignancies in a 3-year follow-up.

Local recurrence was observed in 11 out of 103 patients. This included six (18.8\%) patients with facial paresis and in five $(7 \%)$ patients without. This was not statistically significant (Chi-quadrate test; $p=0.075$ ). The data are shown in Table 5.

Neck node control was $90 \%$ for non-paresis patients and 92\% for patients with nerve paresis. Distant metastases were observed in only two patients, both without impaired nerve function.

The analysis of factors influencing the survival in patients with parotid malignant tumors revealed a statistical significance for shorter survival in the high tumor stages $(p=0.014)$, in high grade histology $(p=0.008)$, and in facial paresis before treatment $(p=0.001)$. Percentage disease-free 3-year survival differed dramatically for advancing tumor (T Stage) and was 85, 90, 70, and $32 \%$ for T1, T2, T3, and T4, respectively (Fig. 1). The percentage disease-free 3 -year survival was 45 and $88 \%$ for patients with and without facial paresis (Fig. 2).

\section{Discussion}

The present study describes one center's 10-year experience with parotid malignancy treatment with a focus on

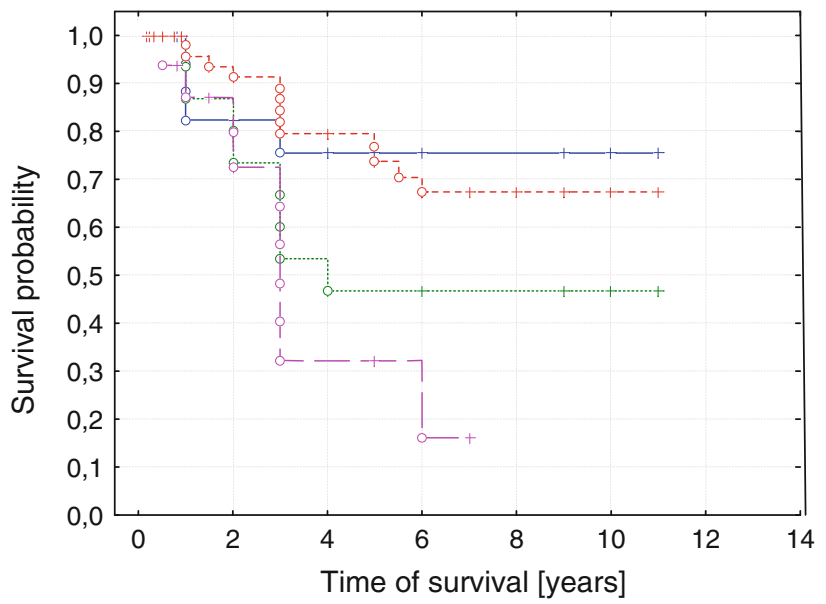

$$
\begin{array}{ll}
--- & \text { T1 } \\
--- & \text { T2 } \\
--- & \text { T3 } \\
--- & \text { T4a } \\
\text { Observations } \\
\text { o complete } \\
+\quad \text { closed }
\end{array}
$$

Fig. 1 Curve of survival probability depending on tumor stage according to Kaplan-Meier

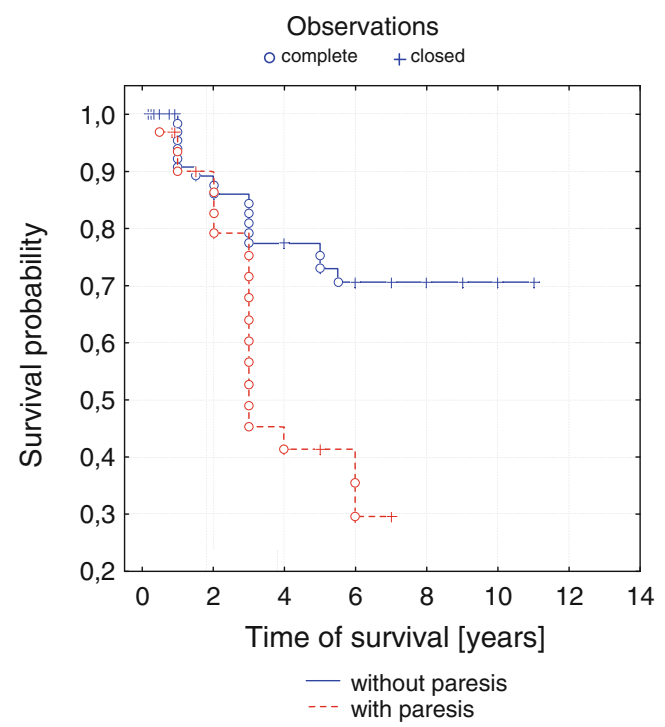

Fig. 2 Curve of survival probability depending on facial nerve paresis according to Kaplan-Meier

facial nerve status. In this retrospective analysis, the authors have taken into consideration patients' age, gender, the duration of complaints (lump and facial paresis), preoperative clinical features of the primary (diameter, skin involvement, total or partial nerve paresis), histologic data, postoperative assessment of specimens, and outcome measures (time until relapse and survival).

In the examined group, facial nerve palsy appeared in nearly $33 \%$ of patients $(32 / 103)$. This included 28 with total paralysis and 4 with partial paralysis. However, of the 
patients with parotid tumors of advanced stage, over $50 \%$ had facial nerve palsy as the presenting and dominant symptom. Facial nerve palsy was the clinical symptom in $60 \%$ of patients with adenoid cystic carcinoma and in $66 \%$ with squamous cell cancer. The paralysis was less frequent $(33.3 \%)$ in cancers developing from mixed tumors. Taking into consideration metastases, O'Brien and co-authors proposed a new staging system for patients with metastatic squamous carcinoma (SCC) to the parotid irrespective of cervical nodal status. In a series of 87 patients, metastases were staged according to the clinical extent of disease in three groups: P1, tumor up to the $3 \mathrm{~cm}$ in diameter; P2, tumor greater than $3 \mathrm{~cm}$ up to $6 \mathrm{~cm}$ in diameter or multiple metastatis parotid nodes; P3, tumor greater than $6 \mathrm{~cm}$ in diameter, VII nerve palsy or skull invasion. Author recommends that the clinical staging system for cutaneous SCC of the head and neck should separate parotid and neck disease [9]. The results of this study demonstrated, that patients with metastatic cutaneous SCC in both the parotid gland and neck had a significantly worse prognosis than those with in the parotid alone. These observations were confirmed in group of 232 patients by Bron et al. [2] and by Andruchow et al. [1] in multicenter study of 322 patients from six different institutions. For metastases to the parotid, none out of our $12(100 \%)$ patients had a facial palsy. A similar observation was made by Moriniere et al. [8], who revealed facial nerve palsy in $33 \%$ of primary malignant tumors and in only $6 \%$ of metastasis to the parotid8. In Terhaard et al.'s [13] analysis describing 324 malignant tumors of the parotid, $27 \%$ of the patients were found with no facial paresis, $14 \%$ were observed with partial paralysis, and $7 \%$ had total paralysis. Preis and co-authors in their research presented a group of 66 patients. They found 8 patients with facial paralysis and in 16 others the infiltration was diagnosed intra-operatively. Salivary duct carcinoma was strongly associated with facial paresis [10].

The assessment of risk factors for facial nerve palsy, in cases of malignant tumors, was presented by Terhaard et al. [13]. There was a statistically significant correlation between facial nerve paralysis and localization in deep lobe, old age, pain, and infiltration of perineurium. Huang et al., based on 60 patients with post-operative weakness of the facial nerve function, showed a significantly higher risk of paresis in operations for cancers greater than $4 \mathrm{~cm}$. Post-operative paresis was also higher in patients with intra-operative signs of nerve infiltration $(95.5 \%)$ versus no infiltration $(51.3 \%)$. The authors mentioned above did not demonstrate a connection between the histology of the tumor and the presence of palsy. However, tumor size, presence in the deep lobe, and nerve infiltration were highly significant [3]. This is confirmed by Preis et al., who recognized the location in the deep lobe and the size of the tumor as important factors. They did not show a correlation with age, sex, pain, and metastases to lymph nodes [10]. Our research demonstrated that facial nerve palsy occurs significantly more in tumors greater than $4 \mathrm{~cm}$. It is well known that malignant infiltration of the facial nerve happens more frequently with a longer duration of symptoms and an advanced stage. A longer duration of symptoms and a delayed initiation of treatment increase the risk of facial palsy, and worsen the outcome. This was confirmed in our research. Despite the fact that the results were not statistically significant, the duration of symptoms in patients with facial nerve palsy was nearly 3 months longer than in patients whose only symptom was a tumor. Non-radical surgery (positive surgical margins) was more prevalent in the paretic group $(25 \%)$ versus the non-paretic group (14\%). Local recurrence was higher in the paresis group (18.8 vs. $7 \%)$. Similar results were presented by Terhaardet al. They demonstrated that facial nerve palsy correlated with a significantly lower percentage of survival, $13 \%$ for total and $37 \%$ for partial paralysis, in comparison to $69 \%$ for patients without paresis [13]. Our study clearly proved a correlation of both $\mathrm{T}$ stage and facial nerve palsy at presentation and the duration of survival of patients with parotid cancer.

The quality of life of the patients after radical removal of the cancer depends on the extent of resection, facial nerve preservation, and the preservation of neighboring structures such as the great auricular nerve, hypoglossal nerve, mandibular nerve, and the lateral wall of the pharynx $[4,11]$.

Removal of one or several of the facial nerve branches leads to long-term functional deficits, and facial muscle atrophy Cable graft techniques and neural repair are vital in the reconstruction and recovery of the resected facial nerve. Muscle rehabilitation is also important to preserve the mass of muscles while they are temporarily deprived of motor innervation $[7,14]$.

In the study from Holland, among 332 patients, the facial nerve was sacrificed in $21 \%$ of patients, and a reconstruction was performed in only $1 / 3$ of those with sacrificed nerves (19/60) [12]. Final results of treatment showed a partial paresis in $22 \%$ of patients and total paresis in $17 \%$. In our analysis, a reconstruction was performed in five patients. Overall, 32 out of 103 were left with permanent facial paralysis, with 28 cases involving all three branches.

\section{Conclusion}

In our study, the incidence of facial nerve palsy due to malignant tumors of the parotid was not correlated with age, sex, duration of symptoms, and histological type of tumors. However, tumor size had a strong statistical correlation with paresis and emphasizes the importance of early diagnosis and treatment to optimize outcome. Facial nerve paresis had 
a very strong prognostic correlation with a poor outcome in the treatment of malignant neoplasm of parotid. Similarly, a high $\mathrm{T}$ stage, and a highly malignant histology, both have a directly negative influence on the patients' survival.

In conclusion, on the basis of analyzed data, prognostic factors concerning pre-treatment risk of facial paresis did not show a correlation with gender, age, duration of history, and tumor histology. However, a longer duration of symptoms and a higher grade histology was observed in paresis group. Increased tumor diameter was the single factor that was statistically correlated with a risk of facial palsy.

Pre-treatment facial nerve status was prognostically significant. Facial nerve impairment before resection was very strongly predictive for a shorter disease-free survival. Facial nerve impairment was correlated with larger tumors and a higher histologic grade of malignancy.

\section{Conflict of interest None.}

Open Access This article is distributed under the terms of the Creative Commons Attribution Noncommercial License which permits any noncommercial use, distribution, and reproduction in any medium, provided the original author(s) and source are credited.

\section{References}

1. Andruchow JL, Veness MJ, Morgan GJ, Gao K, Clifford A, Shannon KF, Poulsen M, Kenny L, Palme CE, Gullane P, Morris C, Mendenhall WM, Patel KN, Shah JP, O’Brien CJ (2006) Implications for clinical staging of metastatic cutaneous squamous carcinoma of the head and neck based on a multicenter study of treatment outcomes. Cancer 106(5):1078-1083

2. Bron LP, Traynor SJ, McNeil EB, O'Brien CJ (2003) Primary and metastatic cancer of the parotid: comparison of clinical behavior in 232 cases. Laryngoscope 113(6):1070-1075

3. Huang CC, Steng FY, Chen ZC, Hsu CJ, Ko JY, Lou PJ, Chen YS (2007) Malignant parotid tumor and facial palsy. Otolaryngol Head Neck Surg 136(5):778-782
4. Kobayashi K, Nakao K, Yoshida M, Ando M, Ebihara Y, Asakage T, Yamasoba T (2009) Recurrent cancer of the parotid gland: how does salvage surgery work for locoregional failure? ORL J Otorhinolaryngol Relat Spec 71:239-243

5. Kopeć T, Szyfter W (2006) Deep lobe of parotid gland tumors. Otolaryngol Pol 60(3):317-324

6. Lin CC, Tsai MH, Huang CC, Hua $\mathrm{CH}$, Tseng HC, Huang ST (2008) Parotid tumors: a 10-year experience. Am J Otolaryngol 29(2):94-100

7. Marchesi M, Biffoni M, Trinchi S, Turriziani V, Campana FP (2006) Facial nerve function after parotidectomy for neoplasm with deep localization. Surg Today 36:308-311

8. Moriniere S, Perie S, Guily JL (2007) Primary and non primary parotid gland malignancies: comparison of treatment modalities and outcomes. Eur Arch Otorhinolaryngol 264:1231-1237

9. O'Brien CJ, McNeil EB, McMahon JD, Pathak I, Lauer CS, Jackson MA (2002) Significance of clinical stage, extent of surgery, and pathologic findings in metastatic cutaneous squamous carcinoma of the parotid gland. Head Neck 24(5):417-422

10. Preis M, Siudry E, Bachar G, Shufel H, Feinmesser R, Shpitzer T (2010) Predicting facial nerve invasion by parotid gland carcinoma and outcome of facial reanimation. Eur Arch Otorhinolaryngol 267:107-111

11. Roh JL, Kim HS, Park CI (2007) Randomized clinical trial comparing partial parotidectomy versus superficial or total parotidectomy. Br J Surg 94(9):1081-1087

12. Terhaard CH, Lubsen H, Van der Tweel I, Hilgers FJ, Eijkenboom WM, Marres HA, Tjho-Heslinga RE, de Jong JM, Roodenburg JL, Dutch Head and Neck Oncology Cooperative Group (2004) Salivary gland carcinoma: independent prognostic factors for locoregional control, distant metastases, and overall survival: results of the Dutch head and neck oncology cooperative group. Head Neck 26(8):681-692

13. Terhaard Ch, Lubsen H, Tan B, Merkx T, van den Laan B, Baatenburg-de Jong R, Manni H, Knegt P (2006) Facial nerve function in carcinoma of the parotid gland. Eur J Cancer 42(16):2744-2750

14. Tsutsumi T, Nakajima N, Hirose T, Watanabe K (2009) Totallength invasion of the facial nerve by parotid carcinoma ex pleomorphic adenoma. Auris Nasus Larynx 36:618-622

15. Tweedie DJ, Jacob A (2009) Surgery of the parotid gland: evolution of techniques, nomenclature and a revised classification system. Clin Otolaryngol 34:303-308 